Melissa Seelye

J. Paul Leonard Library, San Francisco State University, San Francisco, CA, United States

Sara Clarke

Faculty of Information and Media Studies, Western University, London, ON, Canada

Marni Harrington

Faculty of Information and Media Studies, Western University, London, ON, Canada

\title{
Reimagining Scholarly Communication through Experiential Learning: Merging Theory and Practice for MLIS Students (Paper)
}

\begin{abstract}
:
The lack of consistent training for scholarly authors, peer reviewers, and editors is a problem across disciplines, but it is one that affects academic librarians in a unique variety of ways. Like instructional faculty, academic librarians are generally required to engage in scholarly activity, but they are also increasingly in the position of providing guidance on and advocating for emerging trends in scholarly communication. This presentation will describe how the creation of a student-run journal and an associated scholarly communication course in Western University's Faculty of Information and Media Studies (FIMS) are helping to meet this need.
\end{abstract}

\section{Introduction}

The lack of consistent training for scholarly authors, peer reviewers, and editors is a problem across disciplines, but it is one that affects academic librarians in a unique variety of ways. Like instructional faculty, academic librarians are generally required to engage in scholarly activity, but they are also increasingly "in a position to envision, shape, and articulate their future role in scholarly communication" (Carpenter et al., 2011, p. 661). As such, aspiring academic librarians must have both a firm grounding in the practice of scholarly communication and be conversant in its more theoretical dimensions. Students in master of library and information science (MLIS) programs must be empowered with the knowledge and skills to become scholars in their own right who also take an active role in determining the future of scholarly communication. This presentation will describe how the creation of a student-run journal and an associated scholarly communication course in Western University's Faculty of Information and Media Studies (FIMS) are helping to meet this need.

In the fall of 2018, Western's FIMS Graduate Library launched an MLIS student-run journal to provide a publishing venue for students in the MLIS program. The journal, Emerging Library \& Information Perspectives (ELIP), is fully open access and publishes one issue per year, with each publication cycle overseen by a part-time student managing editor employed by the library (Seelye et al., 2019). A team of advisors comprised of librarians, faculty, and publishing professionals provides additional continuity from year to year. At this time, ELIP only accepts submissions from current and recently graduated students in the MLIS program, and it is 
primarily concerned with "fostering a publishing community among emerging librarians and information professionals at Western" (ELIP, n.d.). Because Western's MLIS program does not require students to complete a major research project, ELIP has been envisioned as a platform for a broad range of student work, including original research and critical essays as well as reflective pieces, reviews, and interviews. In addition to engaging students as authors, the journal is integrated into the Scholarly Communication and Open Access Publishing course, with students in that course serving as peer reviewers and assisting with production tasks. There are also opportunities for student volunteers to support the journal, which further expands ELIP's reach within the program.

\section{ELIP and the Human Element of Scholarly Communication}

Too often, scholarly communication and, especially, scholarly publishing are conceptualised in impersonal and transactional terms that do not take the human and relational aspects of the process into consideration. It is even less frequent that the affective dimension of publishing is openly discussed, even though it is a notoriously anxiety inducing process for authors at all points in their careers. ELIP aims to be accessible to first-time authors, and the managing editor and advisors have implemented mentoring opportunities such as drop-in office hours and author workshops to this end. Providing this support network is an important means of helping to mitigate feelings of imposter syndrome as well as the common perception that "research by librarians and archivists is not 'real' research" (Doucette \& Hoffmann 2019, 18).

The feelings of anxiety and vulnerability associated with "putting yourself out there" through publishing are felt all the more intensely by the MLIS students that ELIP works with who generally have not had experience with publishing and often hold limiting notions about who and what can be published. Although MLIS students often have rich work experience in LIS or LIS adjacent fields and/or strong academic backgrounds, it is not uncommon for them to feel unready or ill-prepared to enter their voices into the field's scholarly conversation (Therrell, 2019). Additionally, the current and historic lack of diversity within scholarly publishing (Roh, 2016) may be discouraging to underrepresented students. During the last call for submissions it became apparent that some students held preconceived conceptions about what topics and areas within LIS were suitable for ELIP, and they assumed that work that did not focus on academic libraries and more traditional areas within the field would have no place within the journal. Ultimately, several of the authors who decided to submit work only did so after having multiple discussions with the editor about the publishing process and their work and thereby establishing the requisite sense of safety and trust in ELIP's processes and editorial structure.

The roles of kindness and empathy within LIS are increasingly being examined, and these issues certainly do not fall outside of the realm of scholarly communication. Recently, Dali and Jaeger (2018) have written on the importance of the human aspect of peer review and have discussed "peer review as a space for relationship and community building" (100). We are excited by this refocusing of the discussion around publishing and peer review and believe that it is important for ELIP to both model and encourage students to think about this sort of community-oriented and empathetic approach to scholarly communication. Therefore, we emphasize "kind reviewing" and collegiality in the editorial stages and we strive to provide students with support and mentorship throughout the overarching publishing process. By establishing an infrastructure 
that puts as much care into the publishing process as it does the end result, ELIP offers students a rich experience that, we hope, will inspire them to continue putting their voices and ideas "out there" and advocating for open, inclusive, and kind scholarly communication.

\section{ELIP and Experiential Learning: Bringing Together Theory and Practice}

Although scholarly communication courses are still relatively rare in MLIS programs (Hollister, 2017, p. 10), as Maria Bonn wrote in 2014, "Scholarly communication literacy has become a core competency for academic librarians. We see a growing need for both experts and informed generalists" (p. 132). Thus, rather than simply taking the form of a survey of relevant topics, the Scholarly Communication and Open Access Publishing course at Western aims to actively engage students in scholarly communication processes situated within critical theoretical frameworks. This is accomplished in large part through assignments and activities directly related to ELIP. As discussed in the growing body of literature on student publishing and course journals in particular, student-run journals provide ample experiential learning opportunities (see, e.g., Bauer et al., 2009; Hare, 2019; and Shuttleworth et al., 2019). Moreover, grounding scholarly communication topics in real-world activities helps to avoid pitfalls that arise in relation to MLIS research methods courses, which have been criticized for failing to prepare students "to responsibly consume and competently produce research" (Mandel, 2017, p. 200).

One of the primary ways in which students in the course engage with ELIP is through the peer review process. Informed by ELIP's guidelines, tips from the managing editor, a lesson focused on the history and future of peer review, and sample open peer review reports, students first practice providing constructive feedback on shorter reflective pieces, reviews, and interviews. From there, they conduct formal reviews of article-length submissions, engaging with their peers to discuss their assigned submissions, and ultimately submitting individual reports as well as publication recommendations, which are shared anonymously with the authors. Students take this work seriously, and as others have argued, the "real-world implications" of the assignment do seem to make "the learning more profound" (Chittum \& Bryant, 2014, p. 475). Although ELIP relies on a double-blind peer review model, students simultaneously engage in discussions of the advantages and disadvantages of blind peer review. Additionally, the student reviewers gain an appreciation for the amount of work involved in peer review and often critically reflect on the publishing industry's reliance on volunteer labour, which drives future discussions of the economics of scholarly communication.

Production activities afford another experiential learning opportunity for students in the course as well as others in the program who volunteer to participate. With an emphasis on quality control, students conduct fact and citation checking as well as copy-editing. These activities give students an applied understanding of academic writing standards, which is very valuable given the relative lack of training in this area (Ondrusek, 2012). Similar to the peer review process, this work also helps to demystify the behind-the-scenes aspects of publishing that are often taken for granted. The time-intensive nature of the production activities opens students' eyes to the fact that high caliber online-only publishing requires a significant amount of editorial support and is not simply a matter of uploading author accepted manuscripts to a publishing platform. Students who engage in these activities as well as the peer review process will, when in the field, have a 
realistic understanding of the resources required to support student and faculty journals or launch an academic press.

\section{Conclusion}

MLIS programs have a responsibility to both prepare students to actively engage in the profession as scholars and provide sufficient scholarly communication training to aspiring academic librarians. As noted in the "NASIG Core Competencies for Scholarly Communication Librarians," "Variety is the only constant in the job duties of SCLs [scholarly communication librarians] and responsibility for the full suite of competencies is beyond the reach of even the most accomplished librarian" (NASIG 2017). This work will become increasingly dispersed as more academic libraries re-envision themselves as not just content providers, but also producers of content. Opportunities for librarians to lend strategic direction to campus-based, academy-led publishing initiatives will continue to grow in number as well as scope, and MLIS graduates should be equipped for high profile roles in this changing landscape.

It is not unusual for MLIS programs to include coursework that addresses the objectives of the open access movement and its two dominant models (green and gold), as well as some of the drawbacks of commercial publishing. Additionally, several MLIS programs, including the iSchools at the University of Toronto and San José State University, support student-run journals, which can go a long way towards nurturing emerging scholars. However, Western's approach is unique in that it is grounded in a concerted effort to integrate theory with practice. By creating numerous opportunities for practical engagement in the scholarly publishing process and integrating ELIP's workflows into the curriculum, Western's model is intended to familiarize as many MLIS students as possible with a praxis-oriented approach to scholarly communication.

\section{Reference List:}

Bauer, B. J., Ogás, W. C., Shakir, O. R., \& Oxley, Z. M. (2009). Learning through publishing The Pi Sigma Alpha Undergraduate Journal of Politics. PS: Political Science \& Politics, 42(3), 565-569. https://doi.org/10.1017/S1049096509090908

Bonn, M. (2014). Tooling up: Scholarly communication education and training. College \& Research Libraries News, 75(3), 132-135. https://doi.org/10.5860/crln.75.3.9087

Carpenter, M., Graybill, J., Offord, J.,Jr, \& Piorun, M. (2011). Envisioning the library's role in scholarly communication in the year 2025. Portal: Libraries and the Academy, 11(2), 659-681. http://dx.doi.org.proxy1.lib.uwo.ca/10.1353/pla.2011.0014

Chittum, J. R., \& Bryant, L. H. (2014). Reviewing to learn: Graduate student participation in the professional peer-review process to improve academic writing skills. International Journal of Teaching and Learning in Higher Education, 26(3), 473-484. Retrieved from http://www.isetl.org/ijtlhe/pdf/IJTLHE1984.pdf

Dali, K., \& Jaeger, P. (2018). Beyond scholarly publishing: The human dimension of peer review in LIS. The Library Quarterly, 88(2), 99-124. https://doi.org/10.1086/696578 
Doucette, L., \& Hoffmann, K. (2019). Conceptions of research among academic librarians and archivists. Canadian Journal of Academic Librarianship, 5, 1-25. https://doi.org/10.33137/cjalrcbu.v5.30417.

Emerging Library \& Information Perspectives. (n.d.). Aims \& scope. Retrieved from https://ojs.lib.uwo.ca/index.php/elip/about\#Aims\&Scope

Hare, S. (2019). Library publishers as educators: Crafting curriculum for undergraduate research journals. Journal of Librarianship and Scholarly Communication, 7(1), 1-39. http://doi.org/10.7710/2162-3309.2296

Hollister, C. (2017). Perceptions of scholarly communication among Library and Information Studies students. Journal of Librarianship and Scholarly Communication, 5(General Issue), eP2180. https://doi.org/10.7710/2162-3309.2180

Mandel, L. H. (2017). Experiencing research firsthand: The "unclassroom" experiential learning approach to teaching research methods in an LIS master's program. Journal of Education and Information Science, 58(4), 187-201. doi:10.12783/issn.2328-2967/58/4/1

NASIG Executive Board. (2017, August 11). NASIG core competencies for scholarly communication librarians. Retrieved from https://www.nasig.org/site_page.cfm?pk_association_webpage_menu=310\&pk_association_web page $=9435$.

Ondrusek, A. L. (2012). What research reveals about graduate students' writing skills: A literature review. Journal of Education for Library and Information Science, 53(3), 176-188). https://www.jstor.org/stable/23249110

Roh, C. (2016). Library publishing and diversity values: Changing scholarly publishing through policy and scholarly communication education. College \& Research Libraries News, 77(2), 8285. https://doi.org/10.5860/crln.77.2.9446

Seelye, M., Edgar, M., \& Harrington, M. (2019). Learning by doing: Highlighting the successful collaboration between an open access peer-reviewed journal, a scholarly communication class, and a supportive library. College \& Research Libraries News, 80(9), 502. https://doi.org/10.5860/crln.80.9.502

Shuttleworth, K., Stranack, K., \& Moore, A. J. (2019). Course journals: Leveraging library publishing to engage students at the intersection of open pedagogy, scholarly communications, and information literacy. Partnership, 14(2). https://doi.org/10.21083/partnership.v14i2.5339

Therrell, G. (2019, February 26). “Okay, but can I actually do this?” Diving into publishing as a graduate student. The Librarian Parlor. https://libparlor.com/2019/02/26/okay-but-can-iactually-do-this/ 